\title{
Efficient Gene Transfection into Mammalian Cells Mediated by Cross-linked Polyethylenimine
}

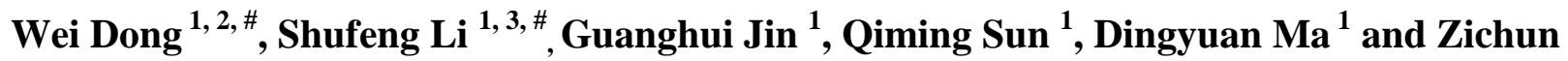 \\ Hua $^{1, *}$
}

1 The State Key Laboratory of Pharmaceutical Biotechnology, College of Life Science, Nanjing University, Nanjing 210093, Jiangsu, P. R. China

E-mail: jinggh75@yahoo.com.cn, sqming1@yahoo.com.cn

2 The School of Chemical Engineering, Nanjing University of Science and Technology, Nanjing 210094, Jiangsu, P. R. China

E-mail: dongwei@mail.njust.edu.cn

3 College of Basic Medical Science, Southeast University, Nanjing 210009, Jiangsu, P. R. China E-mail: shufengli2000@sohu.com

\# These authors contributed equally to this article.

* Author to whom correspondence should be addressed; E-mail: zchua@nju.edu.cn, Tel: 86-2583324605, Fax: 86-25-83324605. Postal address: The State Key Laboratory of Pharmaceutical Biotechnology, College of Life Science, Nanjing University, Nanjing 210093, Jiangsu, P. R. China

Received: 15 December 2006 / Accepted: 31 January 2007 / Published: 14 February 2007

\begin{abstract}
Da}$ branched polyethylenimine (PEI) has successfully been used for in vitro and in vivo gene delivery approaches, but it is cytotoxic. Smaller PEIs are usually noncytotoxic but less efficient. In order to enhance the gene delivery efficiency and minimize cytotoxicity of PEI, we explored to synthesize cross-linked PEIs with degradable bonds by reacting amines of small branched 2000 Da PEI with small diacrylate (1,4-butanediol diacrylate or ethyleneglycol dimethacrylate) for 2-6 hours. The efficiency of the cross-linked PEIs during in vitro delivering plasmid containing enhanced green fluorescent protein (EGFP) gene reporter and their cytotoxicity were assessed in melanoma B16F10 cell and other cell lines. In vivo gene delivery efficiency was evaluated by direct injection delivery of the EGFP plasmid/ cross-linked PEI complexes into mice and by estimating the EGFP expression in animal muscles. Compared to commercially available 25-kDa branched PEI, the cross-linked PEIs reported here could mediate more efficient expression of reporter gene than the 25-kDa PEI control, 19-fold more efficiently in B16F10 cells, 17-fold in 293T cells,
\end{abstract}


2.3-fold in $3 \mathrm{~T} 3$ cells, and they exhibited essentially nontoxic at their optimized condition for gene delivery. Furthermore the transfection activity of polyplexs was preserved in the presence of serum proteins. The muscle transfected with the cross-linked PEI prepared here exhibited normal morphology and excellent gene expression. The cross-linked PEIs reported here were evidently more efficient than the commercial 25-kD PEI control and had less cytotoxicity in gene delivery in vitro and in vivo.

Keywords: Polyethylenimine; Gene delivery; Degradable; Cytotoxicity; B16F10; Mouse muscle.

\section{Introduction}

Although viral vectors are able to remain relatively efficient gene delivery in vivo, and generally yield higher gene expression, there are much concerns over the immunogenic, cytotoxic, and recombinogenic potentials of viral gene transfer [1,2]. Due to the improved safety profile and ease of preparation and manipulation, synthetic alternatives for gene delivery have been extensively explored $[3,4]$. In particular, much progress has been made with cationic polymers such as poly(lysine) [5], polyethylenimine [6] and cationic liposomes [7]. These systems, however, have significant cytotoxicity issues, in part due to the poor biocompatibility of nondegradable polymers [8,9]. Consequently, recent attention has focused on the development of biodegradable cationic polymers [10-17], but gene delivery using these biodegradable polycations has only achieved limited success. One of the most successful and widely studied gene delivery polymers reported to date is polyethylenimine (PEI). It is a cationic polymer which has proven to be an effective transfection agent both in vitro [18, 19] and in vivo [20,21]. Due to its relatively high gene delivery efficiency [19,22,] and ready availability, branched, 25-kDa PEI has become a benchmark to which other polymers [23], especially newly designed and synthesized materials, are often compared. Recent reports indicate that a degradable analogue of $25-\mathrm{kDa}$ branched PEI was produced by conjugating amino groups on $800 \mathrm{Da}$ PEI to diacrylates and this molecule showed high efficient gene delivery capability together with low toxicity [17]. Inspired by this molecule, we designed the molecules to be endowed with both the favorable low toxicity properties of the low molecular weight PEI and the higher transfection efficiency of high molecular weight PEI by coupling low molecular weight 2000 Da PEIs together to form conjugates of high molecular weight PEI using short diacrylate linkages. The molecules were provided with biodegradable ability because of containing ester bonds, it was proved that the ester bonds can be hydrolyzed under physiological conditions. This will facilitate gene transfection of the cross-linked PEIs in vivo. Among the degradable PEI derivatives we synthesized, three degradable polyethylenimines were selected and validated with low toxicity and highly efficient gene delivery for B16F10, 293T and 3T3 cell lines.

In this study, we also optimize the conditions for gene delivery to B16F10 cell and other cells using branched, 25-kDa PEI and the degradable analogues of $25-\mathrm{kDa}$ branched PEI produced by addition of amino groups on 2000-Da PEI to diacrylates. The feature of the transfection protocol was carefully optimized including the volume of the PEI/DNA complexation solution, the forming time of 
PEI/DNA complexation solution and ratio of PEI/DNA. We also studied the effective condensation of DNA by gel retardation assay and dynamic light scattering. The gene transfection introduced by $25 \mathrm{kDa}$ branched PEI and the cross-linked PEIs in mouse leg muscles was observed and assessed by fluorescence microscopy.

\section{Results}

\subsection{Synthesis of cross-linked polyethylenimines}

By conjugating amino groups on branched 2000 Da PEI to ethyleneglycol dimethacrylate (EGDMA) or 1, 4- butanediol diacrylate (BDDA) for 2, 3, 4, 6 hours respectively, the polymers were obtained as follows: EGDMA-PEI 2000-2h; EGDMA-PEI 2000-3h; EGDMA-PEI 2000-4h; EGDMA-PEI 20006h; BDDA-PEI 2000-2h; BDDA-PEI 2000-4h; BDDA-PEI 2000-6h (solidified). The viscosity of reaction solution increased with the reaction time, and it implied that the molecular weight of product became bigger and bigger. Polymerization reached plateau when the reaction time was above 6 hours and the polymers became solidified. ${ }^{1} \mathrm{H}$ NMR $\left(500 \mathrm{MHz}, \mathrm{D}_{2} \mathrm{O}\right)$ analysis showed that the peak of double bond $\mathrm{H}\left(\mathrm{CH}_{2}=\mathrm{C}\left(\mathrm{CH}_{3}\right)-5.66-6.39 \mathrm{ppm}\right)$, in ethyleneglycol dimethacrylate, is completely disappeared in EGDMA-PEI 2000-2h, and the cross-linking was confirmed by verifying extensive ester bond formation ( $\mathrm{H}$ signal for next to the carbonyl group $-\mathrm{CH}_{2}-\mathrm{CH}\left(\mathrm{CH}_{3}\right)-\mathrm{C}=\mathrm{O} 2-3 \mathrm{ppm}$ ) in the final product. ${ }^{1} \mathrm{H} \mathrm{NMR}\left(500 \mathrm{MHz}, \mathrm{D}_{2} \mathrm{O}\right)$ analysis showed that the peak of double bond $\mathrm{H}\left(\mathrm{CH}_{2}=\mathrm{CH}-5.89\right.$ $6.59 \mathrm{ppm}$ ) in 1, 4-butanediol diacrylate completely disappears in BDDA-PEI 2000-4h, and the crosslinking was confirmed by verifying extensive ester bond formation in the final product using ${ }^{1} \mathrm{H}$ NMR (Figure 1).

A<smiles>C=CC(=O)OCCCCOC(=O)C=CCCCNCCC(=O)OCCCCOC(=O)CCNCCC</smiles><smiles>CCCNCCC(C)C(=O)OCCOC(=O)C(C)CNCCC</smiles> 
$\mathbf{B}$

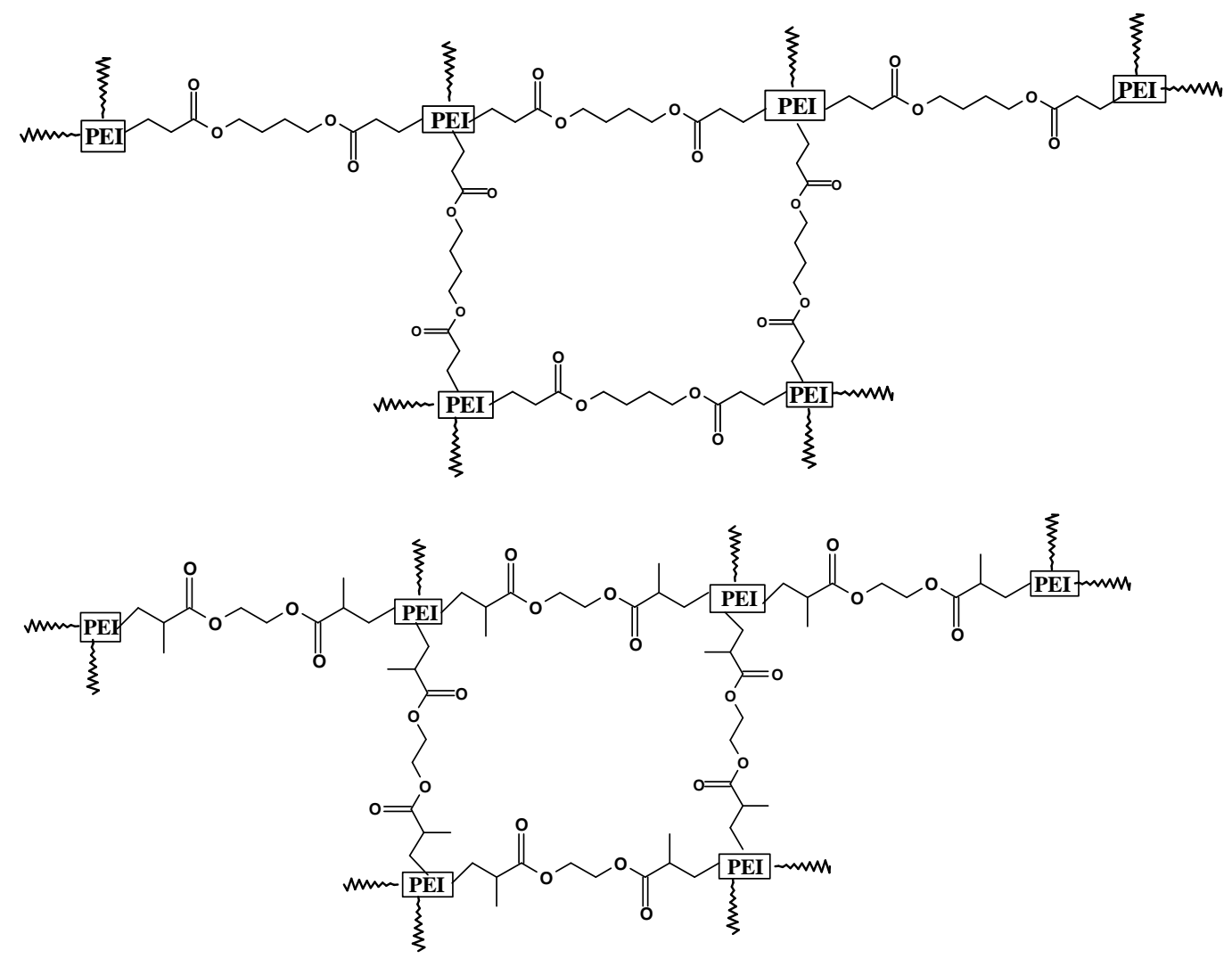

Figure 1. Synthesis of cross linked PEIs and their structural illustration. (A) 2000-Da PEI is reacted with diacrylates (BDDA or EGDMA shown) to generate the ester-cross-linked polymers. (B) The acrylate groups can react with either primary or secondary amines, resulting in a highly branched structure.

\subsection{Cross-linked PEIs Complexs}

To demonstrate whether the cross-linked PEI was possessed of PEI/DNA complex formation ability, agarose gel electrophoresis was employed to analyze the complex formation properties. The results showed that cross-linked PEIs did not appear to affect its ability to condense DNA (data not shown). Dynamic light scattering analysis showed that EGDMA-PEI 2000-2h, EGDMA-PEI 2000-4h and BDDA-PEI 2000-4h complexed with DNA formed smaller particles than 25-kDa PEI/DNA in ddH $_{2} \mathrm{O}$, over the ratio range of polymer:DNA ratios examined (Figure 2). The three cross-linked PEIs formed complexes with diameter ranging from $70-150 \mathrm{~nm}$ in $\mathrm{ddH}_{2} \mathrm{O}$, and could remain stable for hours, moreover EGDMA-PEI 2000-4h polyplexes remain compact for at least $15 \mathrm{~h}$, while 25-kDa PEI polyplexes was evidently unstable and over a period of 1 hour, it yields larger complexes over $300 \mathrm{~nm}$. In previous reports, for efficient endocytosis and transfection to occur, the complexes must be small and compact and polyplexes in no more than $200 \mathrm{~nm}$ are efficiently endocytosed by cells [24, 25]. Many other research groups report that salt-free PEI/DNA complexes remained small and had reduced transfection efficiency as compared to PBS generated complexes [26,27]. We also found that complexes in PBS had high transfection efficiency, but in comparison, the particles in PBS aggregated within several hours to yield larger complexes with diameters around 1-2 $\mu \mathrm{m}$. 25-kDa PEI polyplexes in PBS was extremely unstable and became bigger and bigger after $10 \mathrm{~min}$, this explains why the forming time of 25-kDa PEI /DNA complexation solution is optimally $10 \mathrm{~min}$ for gene delivery, but the transfection efficiency is very low when the forming time of $25-\mathrm{kDa}$ PEI /DNA complexation 
solution is within $5 \mathrm{~min}$. We thought that the transfection complexes did not form completely in less than 10 min. The polyplexes in PBS formed by three cross-linked PEIs were also unstable, generally the particles in PBS began to become bigger after the formation of $30 \mathrm{~min}$. When EGDMA-PEI 20004h/DNA complexes generated in PBS are added to serum-free culture medium or FCS supplemented medium, the aggregation can be inhibited, and when the complexes generated in PBS are added to growth media with serum, no particle growth was found in hours. As shown in Figure 2B.

A

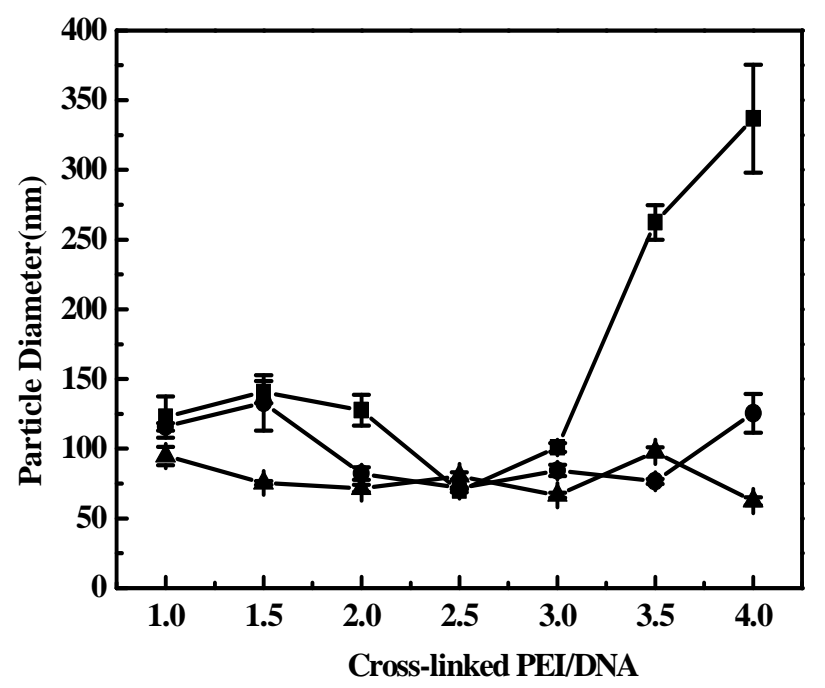

B

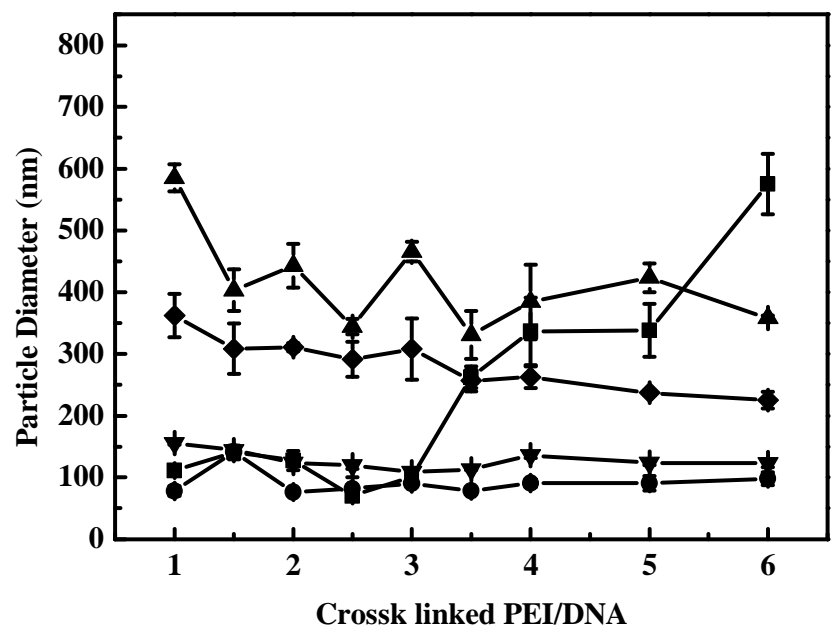

Figure 2. Dynamic light scattering of polymer/DNA polyplexes. $30 \mu \mathrm{g}$ of DNA in $750 \mu \mathrm{ddd} \mathrm{H}_{2} \mathrm{O} / \mathrm{PBS}$

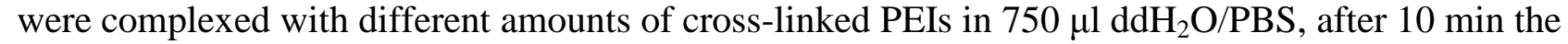
polyplexes were disperse into different culture medium. Then after $30 \mathrm{~min}$, complex size was measured with particle size analyzer as described in Materials and Methods. (A) - - -: Branched 25-kDa PEI in

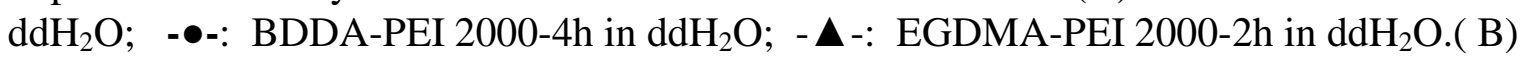

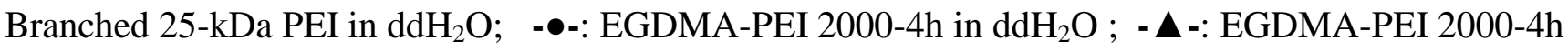
in PBS; - $\boldsymbol{\nabla}$-: EGDMA-PEI 2000-4h in PBS and DMEM with 10\% FCS; - -: EGDMA-PEI 2000-4h in PBS and DMEM without $10 \%$ FCS. ( $N=3$, error bars represent standard deviation) 


\subsection{Optimization of transfection conditions}

Evaluation of the transfection effect of these polymers for B16F10 cell was performed by complex formation and transfection as described above. We firstly optimized the gene delivery or experimental transfection condition by using 25-kDa PEI as model carrier and B16F10 as recipient cell. The optimal condition for gene delivery into B16F10 cell using branched 25-kDa PEI was as follows: the volume of complexation solution was $100 \mu \mathrm{l} /$ well in 24-well plates; the ratio of DNA/PEI was 1:3 (w/w); plasmid dosage was $2.0 \mu \mathrm{g}$ per well in 24-well plates; the forming time for PEI/DNA complexes was $10 \mathrm{~min}$ and after that the complexes were diluted by $200 \mu \mathrm{l}$ DMEM without $10 \%$ FCS. After B16F10 cell was transfected for $4 \mathrm{~h}$ in serum-free medium, the cell was incubated for $24 \mathrm{~h}$ in normal DMEM medium. Under the above optimal condition, we also examined the transfection efficiency of gene delivery into other cell types by using branched 25-kDa PEI (Figure 3A). It revealed that branched 25-kDa PEI is not applicable to $3 \mathrm{~T} 3$ cell and Jurkat cell, and for those cells, the above transfection condition produced less gene delivery efficiency (Figure 3A). Then based on the above optimized transfection condition, we further compared the transfection efficiency of various synthesized cross-linked polymers. Among the polymers, three cross-linked polyethylenimines (EGDMA-PEI 2000-2h; EGDMA-PEI 2000-4h; BDDA-PEI 2000-4h) were found with highly efficient gene delivery in B16F10 cell (Figure 4). The starting material, 2000-Da PEI, induced no measurable gene expression over the range of polymer:DNA ratios investigated (data not shown). This finding is consistent with previous reports, which showed negligible gene expression for PEI with molecular weights below $2000 \mathrm{Da}$ [18].

A

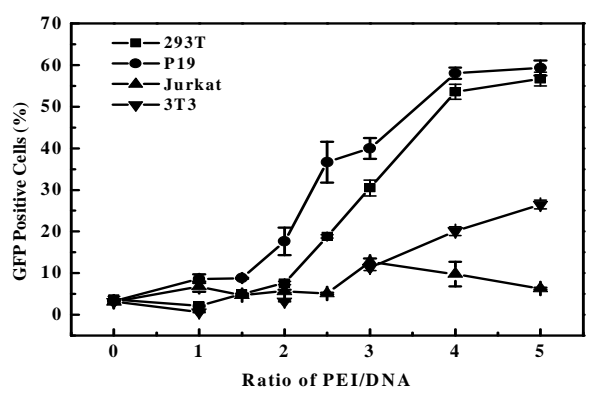

B

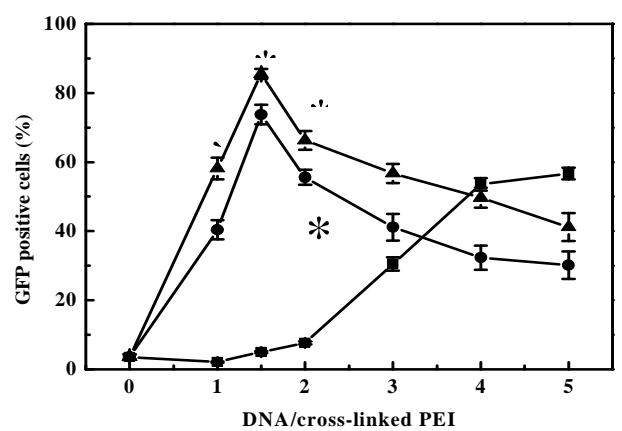

C

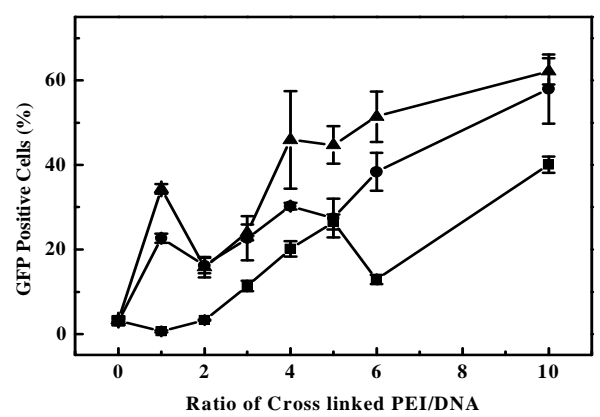


Figure 3. Gene transfection and expression efficiency of cross-linked polymers and 25-kDa PEI in different cell lines. Cross-linked PEIs were used to complex $2 \mu \mathrm{g}$ DNA (pEGFP-C1) in PBS. The cells were incubated with the complexes for $4 \mathrm{~h}$ in serum-free medium, then the cell was incubated for $24 \mathrm{~h}$ in normal DMEM medium, and GFP expression was measured. (A) Gene transfection efficiency of 25-kDa PEI in 293 T, P19, 3T3 and Jurkat cells. (B) Gene transfection efficiency of 25-kDa PEI or

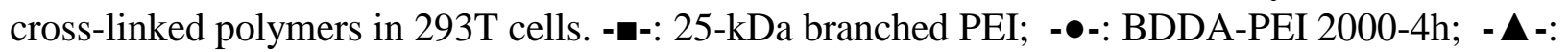
EGDMA-PEI 2000-4h. *, $p<0.01$ as compared to 25-kDa branched PEI. (C) Gene transfection

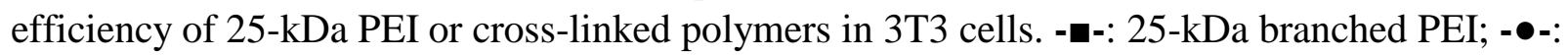
EGDMA-PEI2000-2h; - $\mathbf{\Delta}$-: EGDMA-PEI2000-4h. ( $N=6$, error bars represent standard deviation).

A
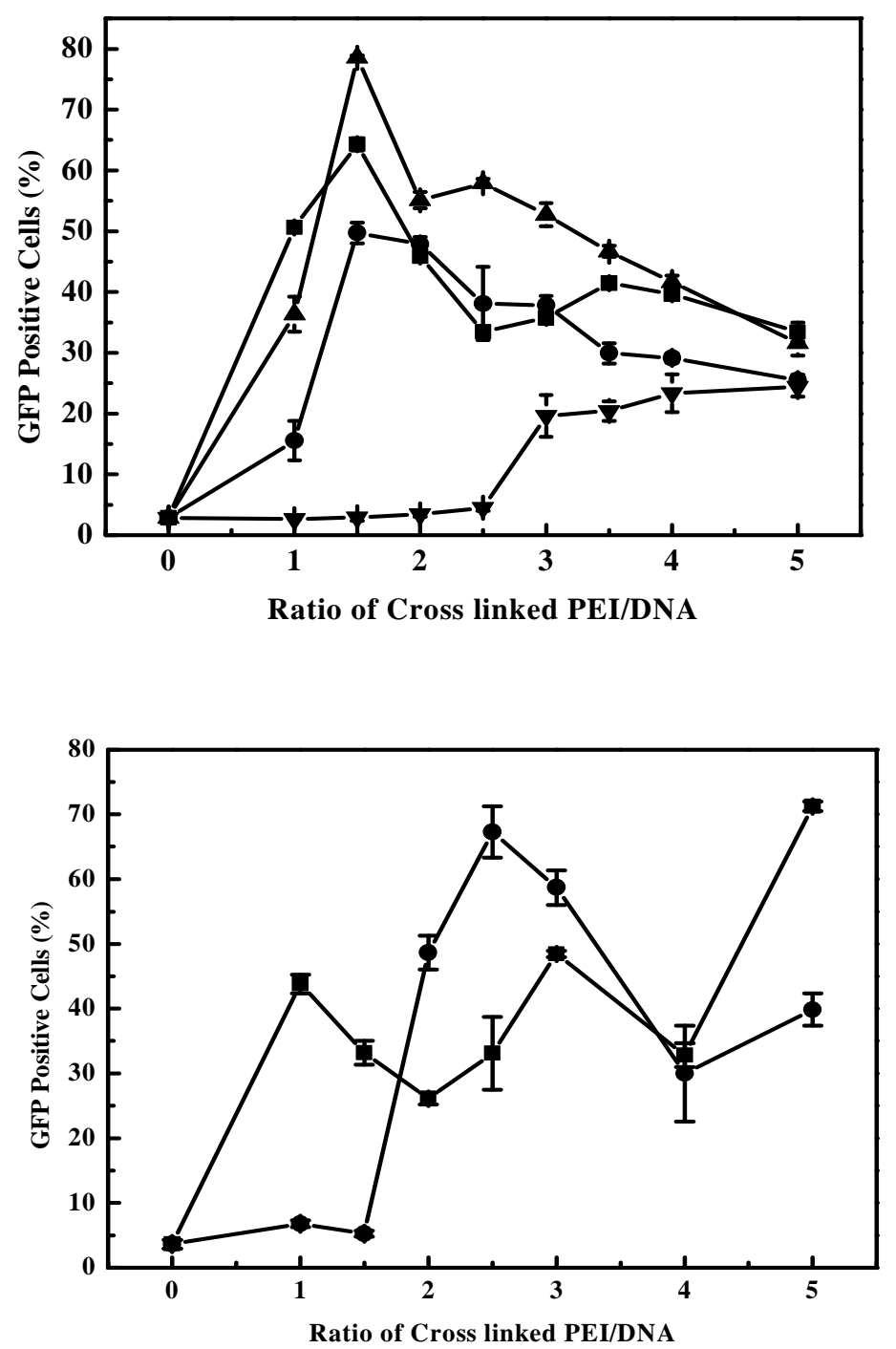

Figure 4. Gene transfection and expression efficiency of cross-linked PEIs in B16F10 cells. Crosslinked PEIs were used to complex $2 \mu \mathrm{g}$ DNA (pEGFP-C1) in PBS. B16F10 cells were incubated with the complexes for $4 \mathrm{~h}$ in serum-free medium, then the cell was incubated for $24 \mathrm{~h}$ in normal DMEM

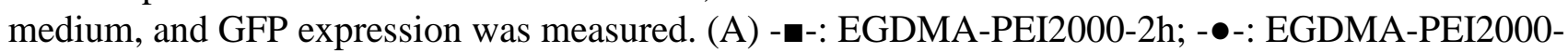

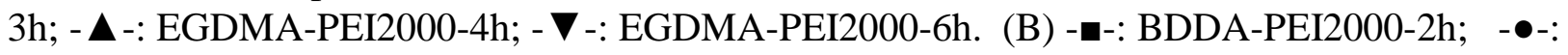
BDDA-PEI2000-4h. ( $\mathrm{N}=6$, error bars represent standard deviation). 
In order to comprehensively evaluate and compare the transfection efficiency of our synthesized polymers, we carried out the gene transfection assays of branched 25-kDa PEI and the three crosslinked polyethylenimines at their optimal polymer/DNA ratios in B16F10 (Figure 5), at the same time their cytotoxicity was also evaluated (Figure 6). For B16F10 cells, we found that compared to 25-kDa PEI, EGDMA-PEI 2000-2h is 19 fold more efficient in transfection and it is essentially nontoxic at the same concentration (DNA/PEI=1:1.5, polymer concentration $10 \mu \mathrm{g} / \mathrm{ml}$ ) (Figure 5, and Figure 6A). BDDA-PEI 2000-4h is 1.3 fold than 25-kDa PEI, meanwhile it exhibits lower toxicity (DNA/PEI=1:2.5, polymer concentration $17 \mu \mathrm{g} / \mathrm{ml}$ ) ( Figure 5 and Figure 6A). EGDMA-PEI 2000-4h mediated gene expression 17 -fold more efficiently than $25-\mathrm{kDa}$ PEI and is less cytotoxic at the same concentration (DNA/PEI=1:1.5, polymer concentration $10 \mu \mathrm{g} / \mathrm{ml}$ ) in $293 \mathrm{~T}$ cells ( Figure 3B, and Figure 6C). EGDMA-PEI 2000-4h mediated gene expression 2.3-fold more efficiently than 25-kDa PEI and is less cytotoxic at the same concentration (DNA/PEI=1:4, polymer concentration approximately 27 $\mu \mathrm{g} / \mathrm{ml}$ ) ( Figure 3C and Figure 6B) in 3T3 cells.

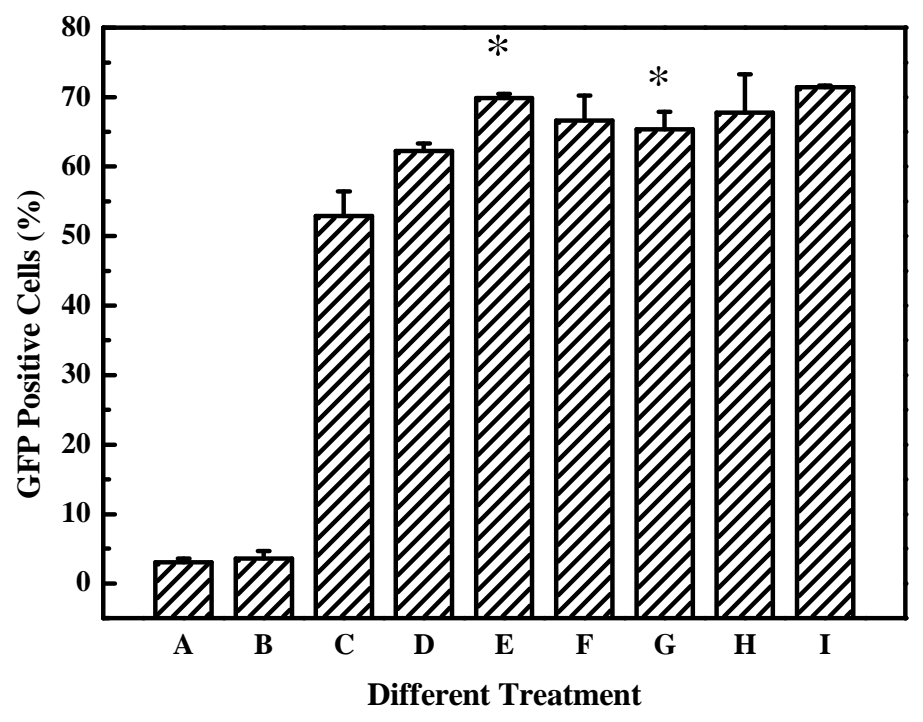

Figure 5. Comparison of the optimal transfection efficiency of cross-linked PEIs and 25-kDa PEI in B16F10 cells. Cells were transfected using optimal conditions established for each vector. ${ }^{*}, p<0.01$ as compared to group $\mathrm{B}$ at the same ratio of DNA/ polymer. A: Control, PBS only, no plasmid, no polymer. B. DNA/25-kDa PEI=1:1.5; C. DNA/25-kDa PEI =1:2.5; D. DNA/25-kDa PEI =1:3; E. DNA/EGDMA-PEI 2000-2h $=1: 1.5$; F.DNA/EGDMA-PEI 2000-2 $\mathrm{h}=1: 3$; G. DNA/EGDMA-PEI 2000-4h =1:1.5; H. DNA/EGDMA-PEI 2000-4h = 1:3; I. DNA/BDDA-PEI 2000-4h =1:2.5. $(N=6$, error bars represent standard deviation). 

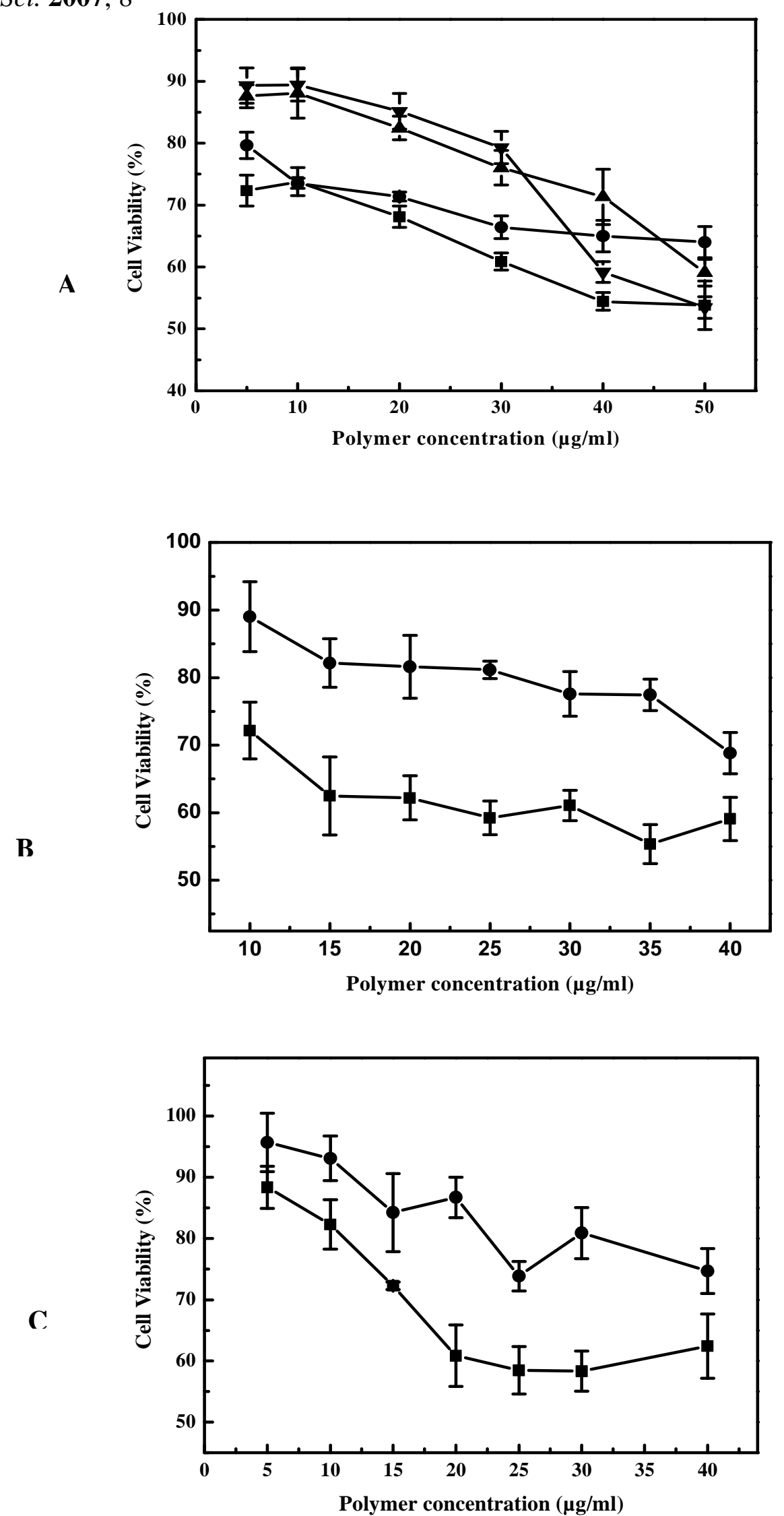

Figure 6. Cytotoxicity of cross-linked PEIs for B16F10, 3T3 and 293T cells. (A) Cytotoxicity of cross-linked PEIs and 25 k-Da PEI for B16F10 cell. -n-: 25 k-Da PEI; - $\bullet-$-: GDMA-PEI 2000-4h; - $\mathbf{\Delta}$-: BDDA-PEI 2000-4h; - $\mathbf{\nabla}$-: EGDMA-PEI 2000-2h. (B) Cytotoxicity of cross-linked PEIs for 3 T3 cell. -匹-: 25k-Da PEI; - -: EGDMA-PEI 2000-4h. (C) Cytotoxicity of cross-linked PEIs for 293T cell. ๓-: 25 k-Da PEI; -•-: EGDMA-PEI 2000-4h. ( $N=8$, error bars represent standard deviation). 


\subsection{Cytotoxicity of cross-linked PEIs}

The cytotoxic profiles of cross-linked polymer were investigated by using MTT assay (Figure 6). The results indicated that EGDMA-PEI 2000-2h and BDDA-PEI 2000-4h were minimally toxic with $89 \%$ and $83 \%$ of cells remaining viable at its optimal polymer concentration (DNA/polymer 1:1.5, polymer concentration $10 \mu \mathrm{g} / \mathrm{ml}$ and DNA/polymer $1: 2.5$, polymer concentration approximately 17 $\mu \mathrm{g} / \mathrm{ml}$ respectively) (Figure $6 \mathrm{~A}$ ) for $\mathrm{B} 16 \mathrm{~F} 10$, meanwhile for $25-\mathrm{kDa}$ PEI, $68 \%$ of B16F10 cells remained viable at the optimal polymer/DNA ratio (DNA/polymer 1:3, $20 \mu \mathrm{g} / \mathrm{ml}$ ) (Figure 6A). The severity order of cytotoxicity for B16F10 cell was 25-kDa PEI > EGDMA-PEI 2000-4h > BDDA-PEI 2000-4h > EGDMA-PEI 2000-2h. For example, EGDMA-PEI 2000-2h was least toxic with $93 \%$ of cells remaining viable at its optimal polymer concentration $(1: 1.5 \mathrm{DNA} /$ polymer, $10 \mu \mathrm{g} / \mathrm{ml}$ polymer concentration) (Figure 3B, Figure 6C) for 293T, in contrast, 25-kDa PEI led to 60\% of cells remaining viable (Figure 6C), almost decreased by $1 / 3$, at the optimal ratio of polymer/DNA for 293T (1:4 DNA/polymer, $27 \mu \mathrm{g} / \mathrm{ml}$ polymer concentration) (Figure 3B, Figure 6C). EGDMA-PEI 2000-4h was also less toxic, with $81 \%$ of cells remaining viable at its optimal polymer concentration (1:4 DNA/polymer, approximately $27 \mu \mathrm{g} / \mathrm{ml}$ polymer concentration) (Figure 3C, Figure 6B) for 3T3, in contrast, 25k-Da PEI led to 59\% of 3T3 cells remaining viable at the same polymer concentration (Figure 6B). Although for different cell lines, the same polymer used at same concentration displayed different gene delivery efficiency, they displayed similar cytotoxicity to various cell types.

In the present study, most of our cross-linked PEIs had less toxic than 25-kDa PEI control. The low toxic property of cross-linked polymers is thought to reflect the biodegradable characteristics of the polymers, which was consistent with several biodegradable cationic polymers investigated in the previous reports $[11,12,16,17]$ and it makes the polymers desirable for practical gene transfer application.

\subsection{Gene expression in vivo}

The cross-linked PEI (EGDMA-PEI 2000-2h) was chosen to demonstrate its efficiency in gene delivery into animal model, C57BL/6J mouse leg muscle. We found that even 5 days after gene delivery, the injected muscle still displayed well-maintained muscular structure and normal morphology, and the injected gene expressed homogeneously at high expression level representing by bright green fluorescence (Figure 7A). However, the muscle transfected with $25-\mathrm{kDa}$ PEI is in striking contrast to the muscle treated with EGDMA-PEI 2000-2h. A great deal of muscular cells transfected with 25-kDa PEI was granulated and in abnormal morphology (Figure 7B). Those evidently exhibited the dramatic difference in toxicity between standard 25-kDa PEI and our designed cross-linked PEI. 
A

Fluorescent microscopic analysis of GFP expression

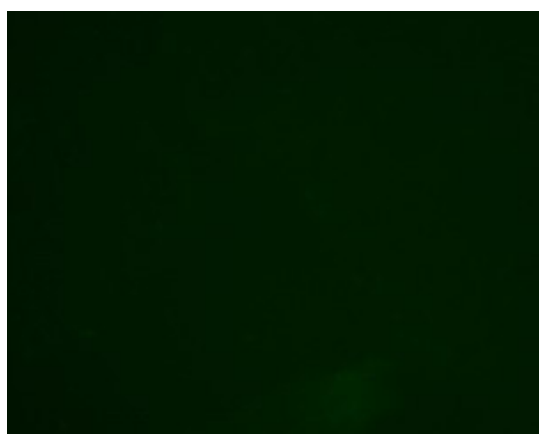

Cross-linked PEI Control (3day)

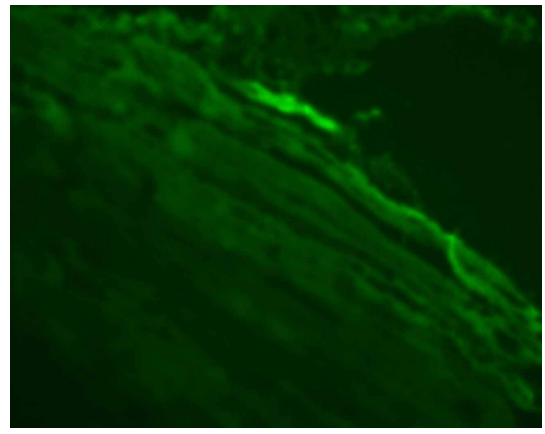

Cross-linked PEI （1day）

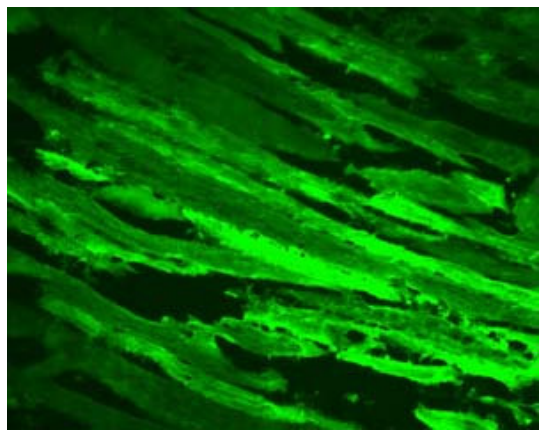

Cross-linked PEI （3 day )

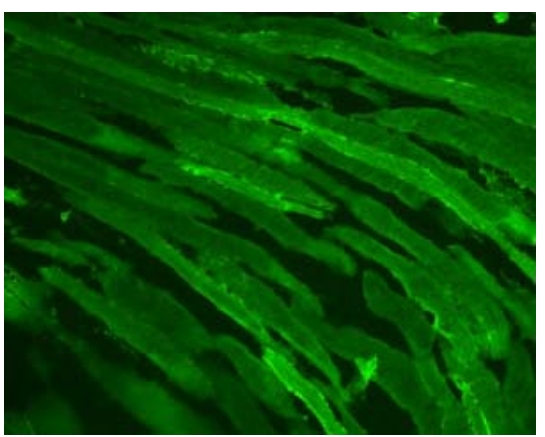

Cross-linked PEI （5 day )
Light microscopic analysis of muscular morphology

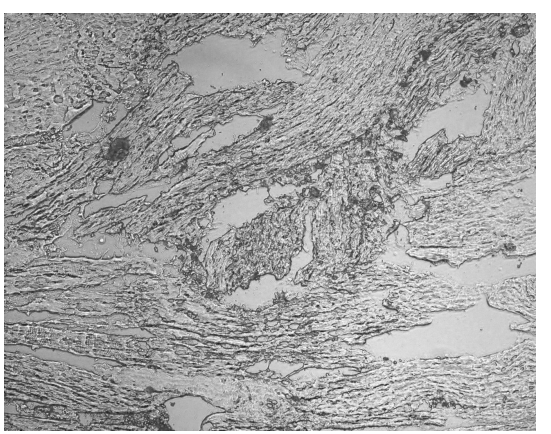

Cross-linked PEI Control (3day)

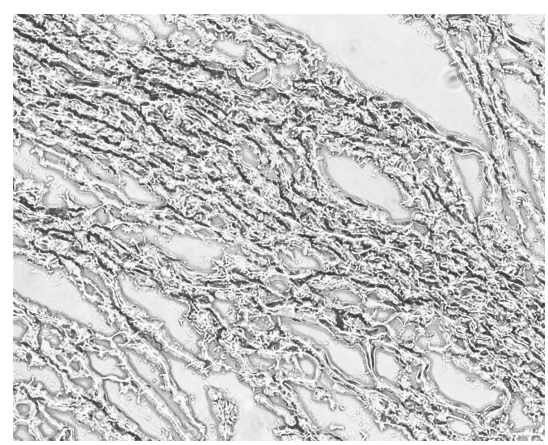

PBS Control (3day)

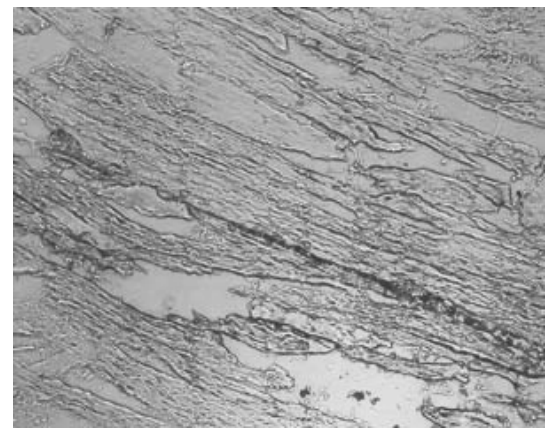

Cross-linked PEI ( 3 day)

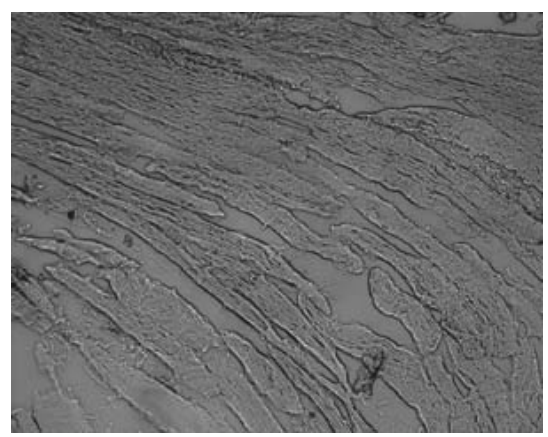

Cross-linked PEI (5 day) 


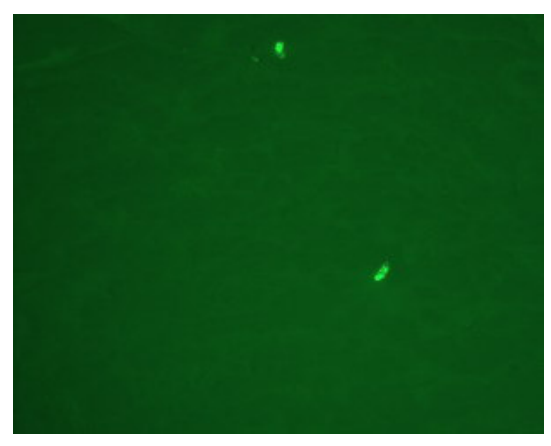

DNA Control (3day)

B

Fluorescent microscopic analysis of GFP expression

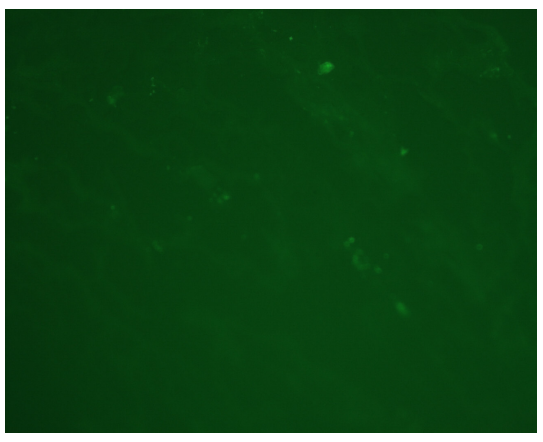

PEI Control (3day)

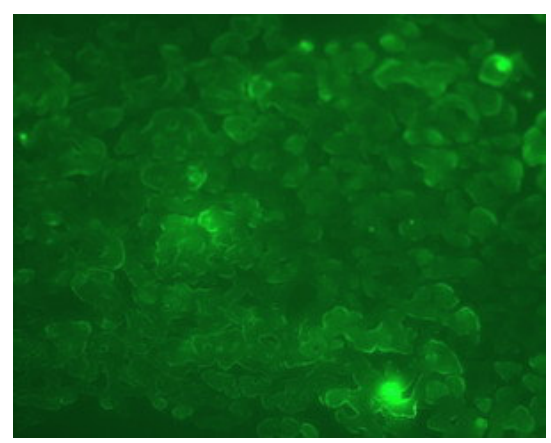

PEI ( 1day)

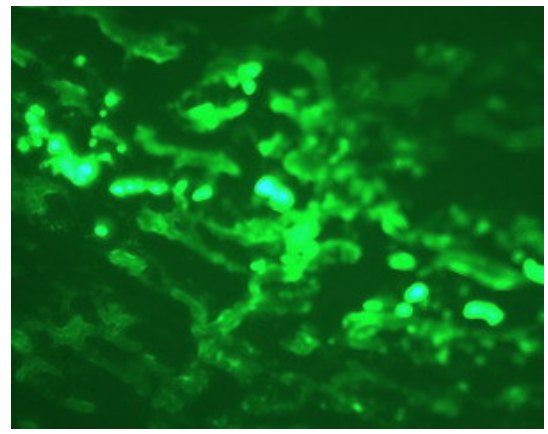

PEI ( 3 day)

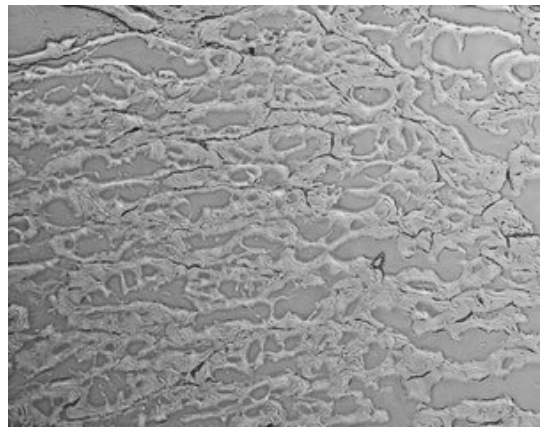

DNA Control (3day)

Light microscopic analysis

of muscular morphology

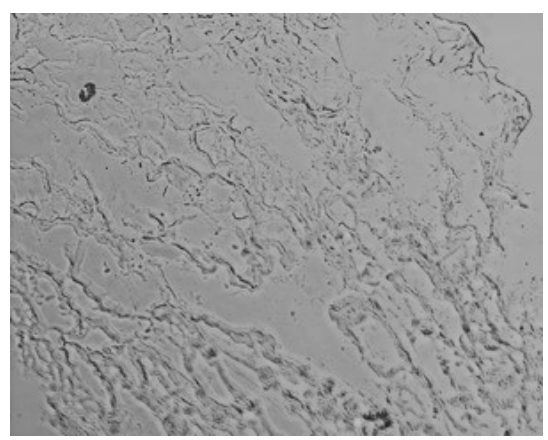

PEI Control (3day)

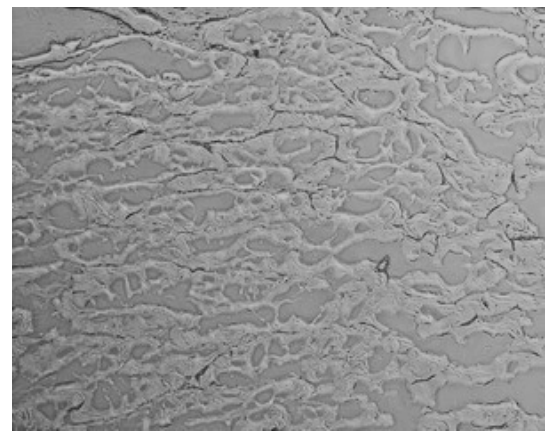

PBS Control (3day)

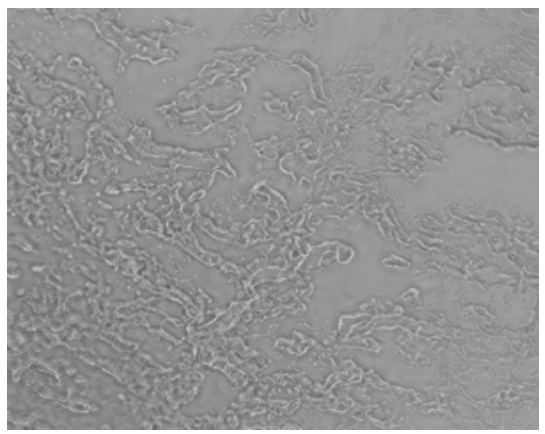

PEI (3 day) 


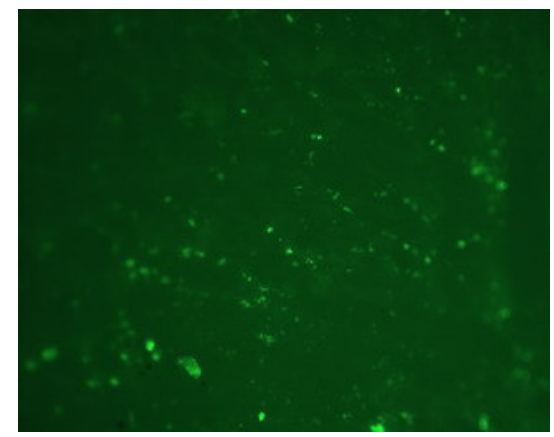

PEI ( 5 day)

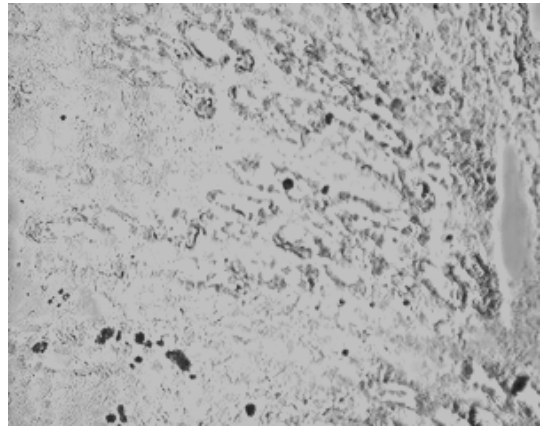

PEI ( 5 day)

Figure 7. The results of gene delivery for mouse muscle with EGDMA-PEI 2000-2h and $25 \mathrm{k}$-Da branched PEI $(\times 20$ original magnification). (A) The results of gene delivery for mouse muscle with

EGDMA-PEI 2000-2h, Control: PBS only, no plasmid, no polymer; Cross-linked PEI Control: Polymer in PBS, no plasmid. DNA Control: plasmid only. (B) The results of gene delivery for mouse muscle with 25 k-Da branched PEI, Control: PBS only, no plasmid, no PEI; PEI Control: PEI in PBS, no plasmid.

\section{Discussion}

The gene delivery efficiency and cytotoxicity of PEI vary with its molecular weight. For example, the branched 2000 Da PEI is several hundred fold less efficient than the branched 25-kDa PEI at the same concentration [28], but the former is not cytotoxic whereas the latter is. We are interested in how to combine the advantages of good transfection capability of high molecule weight PEI and nontoxic property of low molecule weight PEI. We hypothesized that high molecular weight conjugates composed of 2000 Da PEI would yield transfection efficiencies comparable to those obtained with high molecular weight PEI. Furthermore, we expected that when the transfection complexes were exposed to the physiological conditions, the ester bonds introduced by the cross-linking reagents would be hydrolyzed, and the hydrolysis of the ester bonds has been validated under physiological conditions by Forrest et al 2003 [17]. This would promote reversion of the high molecular weight complexes back to their low molecular weight counterparts, presumably leading to lower toxicity and potentially easier access by the transcription machinery. We hoped that optimizing the combination of PEIs and the cross-linking reagents would achieve the enhancement in gene delivery efficiency with minimal cytotoxicity.

The degradable PEIs reported here appears to retain the beneficial function of 25-kDa PEI, but upon degradation we believe the polymers allow for more efficient transcription and interferes less with normal cell functions. As far as the gene delivery into B16F10 cells is concerned, among all the prepared degradable PEIs, the cross-linked product of branched 2000 Da PEI and EGDMA was more highly efficient, this indicated that branched 2000 Da PEI and EGDMA compose better combination of monomer and cross-linking agent. It was reported that $800 \mathrm{Da}$ PEI and 1,3-butanediol diacrylate/1,6- 
hexanediol diacrylate was also better combination of monomer and cross-linking agent [17], but the transfection efficiency is not easy for us to make comparison each other, because the report was confined to the gene expression of luciferase and did not report the percentage of transfected cells. The cross-linked products of 2000 Da PEI and EGDMA was easier to obtain high transfection efficiency in our experiments (Figure 4). These showed that the high efficiency is dependent on the nature of the linkages and the PEIs used. Although the viscosity, an indicator of molecular weight, increased with the elongation of polymerization time, the polymerization time showed less influential on the transfection efficiency of the products for B16F10 cells (Figure 4A). For example, the cross-linked products polymerized for 2 to 4 hours all had better transfection efficiency for B16F10 cell, and it also can apply to other cell lines, for example, EGDMA-PEI 2000-4h exhibited the highest transfection efficiency for 3T3 (Figure 3C), while branched 25-kDa PEI and other cross-linked polymers were less efficient for 3T3. In fact when using the EGFP reporter expression analysis, the complexes of EGDMA-PEI 2000-4h and plasmid in PBS (pH7.4) achieved stable transfection with the average efficiency up to $60 \%$ for all the cell lines we studied, including B16F10, 293T, CHO, EL-4 and Hela (data not shown). For $293 \mathrm{~T}$ and B16F10 cell lines the transfection efficiency was frequently 80-90\%. Therefore EGDMA-PEI 2000-4h displays broad application potential in wide range of cell lines.

As discussed above, the transfection activity of the cross linked PEI is critically dependent on their structure, although molecular weight of polymers is important $[29,22]$. Thomas M. et al reported that moderate enhancement in hydrophobicity increased the transfection efficiency of 25-kDa PEI [28], and Daniel G. et al reported that the most effective cross linked polymers for gene delivery was composed of monomer containing alcohol groups and cross-linking agent of hydrophobic acrylates [30]. But the water-solubility of cross-linked products of PEI 2000 and EGDMA/BDDA was less than 25-kDa PEI, and was also likely less than poly( $\beta$-amino esters) with hydroxy groups. Therefore the cross-linking agent of hydrophilic acrylates seemed to be benifical for gene delivery in our experiments. Zhong Zhiyuan reported that the hydrophobic segments in the polymers likely facilitate cellular uptake on one hand, and lead to cell membrane damage on the other hand via hydrophobic interactions with cell membranes [31]. Thus for the transfection efficiency and cytotoxicity, the hydrophilic-hydrophobic balance of the polycation is also important. Although branched 25-kDa PEI had high gene delivery efficiency to B16F10 and 293T cell at the optimal polymer/DNA ratio between 3 and 4 (Figure 5 and Figure 3A), in general it showed evident cytotoxicity when branched 25-kDa PEI was used in gene delivery to some cell lines with polymer/DNA ratio over 3. Compared to branched 25-kDa PEI, crosslinked PEIs not only had high gene delivery efficiency to B16F10 and 293 cells, but also can delivery gene at lower optimal polymer/DNA ratios (Figure 5 and Figure 3B), so they had low cytotoxicity. Generally, lower optimal polymer/DNA ratios are indicative of the greater DNA condensation ability of the polycations and thus the cross-linked PEIs are suitable candidates for in vivo gene delivery. The cross-linked PEI (EGDMA-PEI 2000-2h) for in vivo gene delivery was tested for its efficiency in gene delivery into mouse muscle (Figure 7) and tumor models (data not shown). The results of gene delivery in mouse muscle were showed in Figure 7, the transfection efficiency for muscle is similar to that of Massimo Don's electro-transfection of genes in adult skeletal muscle [32], but our procedure is easier and equipment-free. The gene delivery of mouse tumor model also was studied in our lab and the cross-linked PEI mediated obvious tumor inhibition of RNA interfering plamids [33]. 
25-kDa PEI has been widely studied as DNA condensing agent and transfection vector [3] and is the standard to which new polymeric vectors is often compared [23]. Unfortunately, as outlined above, it is also associated with obvious cytotoxicity and high level of gene expression is usually realized at a substantial cost to cell viability. To determine the toxicity profile of cross-linked PEIs, we conducted MTT assay for B16F10, 293T and 3T3 cell lines, and the results are compared with 25-kDa PEI's. The results of MTT assay showed that the cell viability of cross-linked PEIs was more than that of 25-kDa PEI with the increase of $21 \%, 22 \%, 33 \%$ for B16F10, 3T3 and 293T respectively, the cytotoxicity of cross-linked PEI was evidently less than $25 \mathrm{kDa}$ PEI in the process of gene transfection. On the other hand biodegradability is very beneficial when these polymers used in vovo, this can be proved in the gene transfection experiment of mouse's muscle (Figure 7). Detailed investigations of the molecular weight weight and the degradation rate of the synthesized polymers with different nature of the linkage groups are in progress.

In general, serum was usually present in the transfection medium. The transfection activity of crosslinked PEIs prepared here was preserved or increased in the presence of serum proteins (Figure 8), this is convenient for application in vitro, and this characteristic is also important, even necessary, for its application in vivo. We therefore investigated the effect of different DMEM (with/without 10\% FCS) on polyplex particle size and the influence of polyplex particle size on transfection efficiency. As shown in Figure 2B, when the polyplexes were prepared in PBS with EGDMA-PEI 2000-4h and DNA, after 10-15 minutes they were added into DMEM with 10\% fetal calf serum and the particle size of the polyplexes was as small as that of polyplexes prepared in $\mathrm{ddH}_{2} \mathrm{O}$. The particle size did not increase during a 4-h period after mixing DNA and EGDMA-PEI 2000-4h, but after $10 \mathrm{~h}$ we found that aggregation has occurred and all polyplexes sank into the bottom of cuvette. The particle size was larger $(>300 \mathrm{~nm}$ ) and a gradual increase in particle size was observed when polyplexes were added to serum-free DMEM, and aggregated over a period of hours to yield larger complexes with diameters in the range of 1-2 $\mu \mathrm{m}$. But the transfection efficiency was high, this showed that small particle size is not an absolute criterion for transfection [27, 34]. When DMEM supplemented with 10\% FCS was added, no particle size growth occurred, suggesting that serum protein could stabilize the particle against aggregation, thus preventing size increase. Similarly Sharma V. K. reported that dilution itself reduced the rate of aggregation of PEI/DNA complexes [35]. Thus we investigated the effect of the amount of DMEM with $10 \%$ FCS on gene transfection efficiency and found that it is beneficial that PEI/DNA complexation solution was diluted by a great deal of growth media when the PEI/DNA complexes were formed after 10-15 min. Prolongation of transfection duration will not improve transfection efficiency, for example, the transfection efficiency of cells transfected for 24 hours did not show much difference from that transfected for 4 hours (Figure 8). It implies that transfection process occurred essentially within 4 hours, and within 4 hours, did not severely aggregate when transfected in free serum medium or with serum medium (Figure 2B). In fact the transfection efficiency of EGDMAPEI2000-4h, EGDMA-PEI2000-2h and BDDA-PEI2000-4h was serum independent, for B16F10 cells and $293 \mathrm{~T}$ cells, the three polymers was identical with Lipofectamine ${ }^{\mathrm{TM}} 2000$ (data not shown) when the transfection was carried out in growth media with $10 \%$ FCS, but the polymers could mediate more efficient expression of reporter gene than the Lipofectamine ${ }^{\mathrm{TM}} 2000$ at their optimal transfection condition for EL-4 and 3T3 cell lines (Figure 9). 


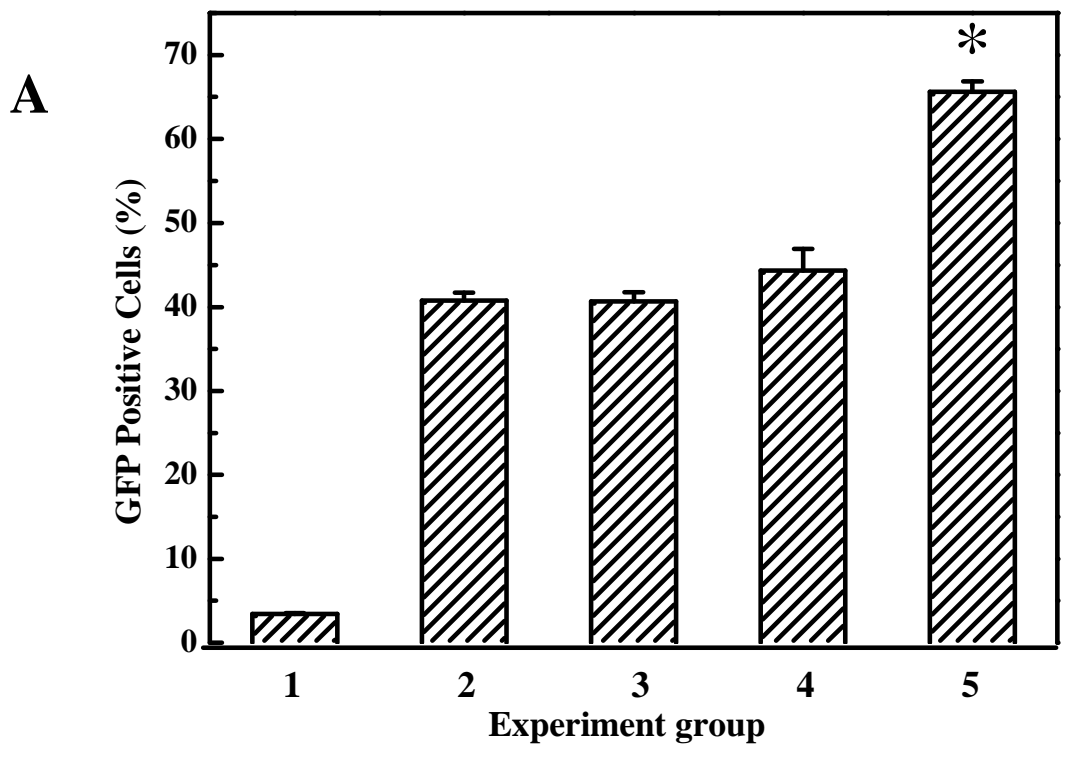

B

\begin{tabular}{lccccc} 
& $\mathbf{1}$ & $\mathbf{2}$ & $\mathbf{3}$ & $\mathbf{4}$ & $\mathbf{5}$ \\
Polyplexes( 10 min) & $\begin{array}{l}100 \mu \mathrm{l} \text { PBS } \\
\text { (No plasmid) }\end{array}$ & $100 \mu \mathrm{l}$ & $100 \mu \mathrm{l}$ & $100 \mu \mathrm{l}$ & $100 \mu \mathrm{l}$ \\
DMEM(with 10\% FCS) & \multicolumn{3}{c}{$300 \mu \mathrm{l}$ (for 4 h) } \\
DMEM (with 10\% FCS) for 24 h & $500 \mu \mathrm{l}$ & $300 \mu \mathrm{l}$ & $300 \mu \mathrm{l}$ & $700 \mu \mathrm{l}$ & $900 \mu \mathrm{l}$
\end{tabular}

Figure 8. (A) The effect of different volume of DMEM on gene expression in CHO cells. (B) The DMEM volume for each group.EGDMA-PEI2000-4h was complexed with $2.0 \mu \mathrm{g}$ DNA in PBS(100 $\mu \mathrm{l}$ volume), then the polyplexes were incubated at $25^{\circ} \mathrm{C}$ for $10 \mathrm{~min}$. The ratio of DNA/EGDMA PEI2000$4 \mathrm{~h}$ was 1:2. CHO cells were transfected in different amount of DMEM and incubated for $24 \mathrm{~h}$. For group 2 , transfection medium was replaced with $300 \mu$ l growth medium $4 \mathrm{~h}$ post transfection. ${ }^{*}, p<$ 0.01 as compared to the condition of groups of $2,3,4 . N=6$, error bars represent standard deviation. 
A

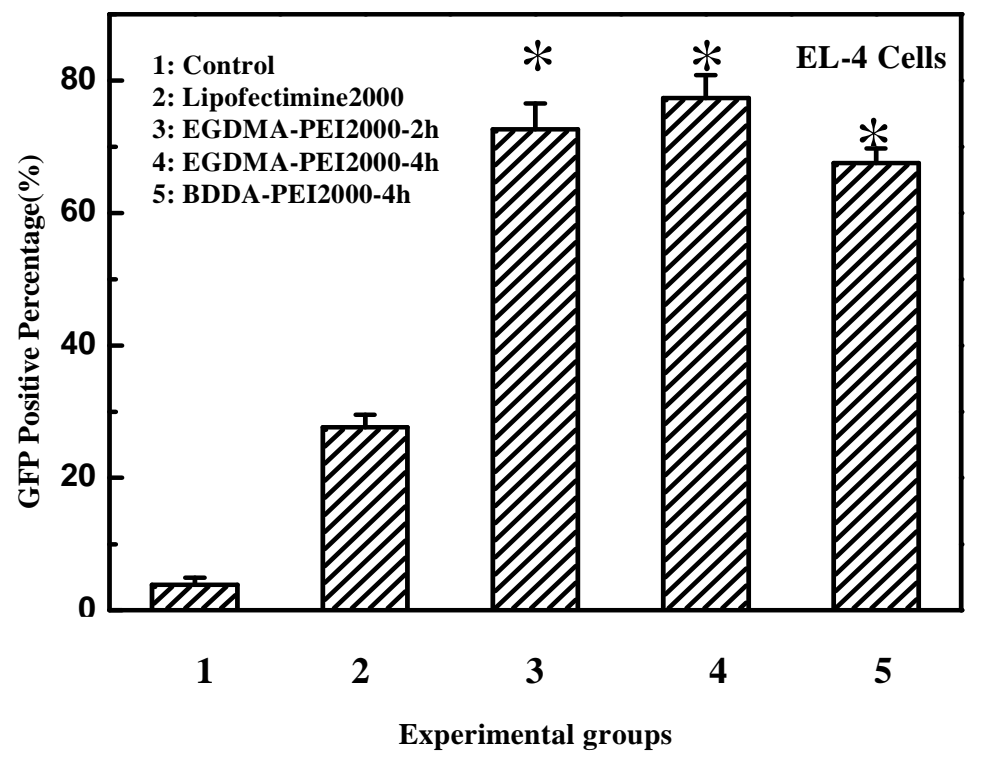

B

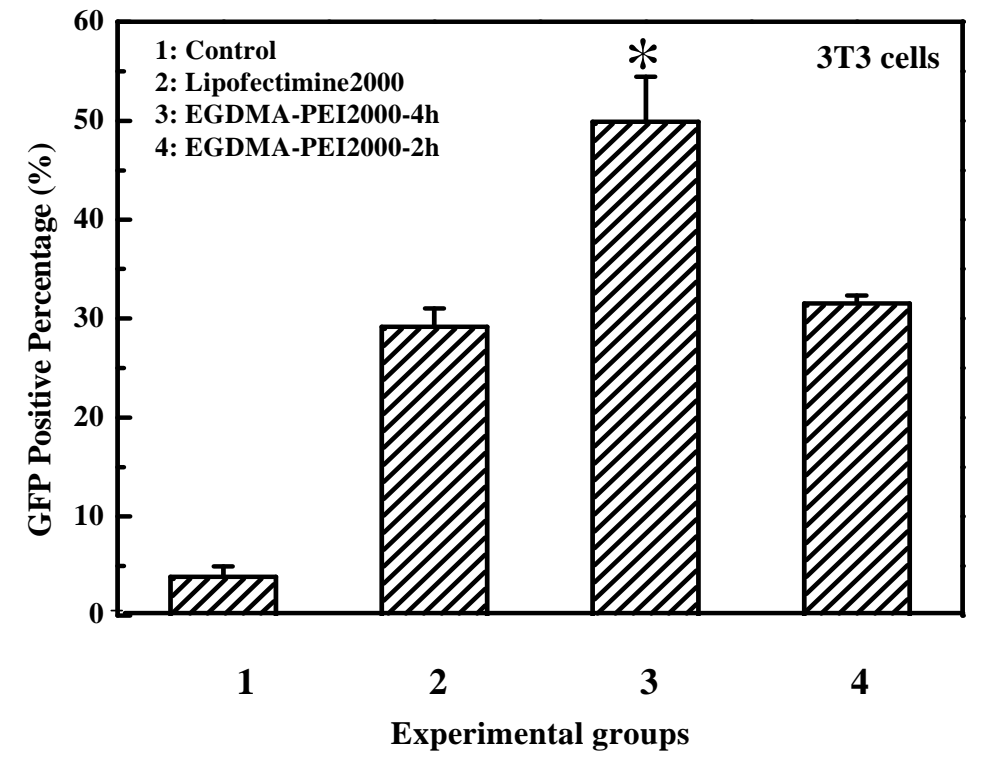

Figure 9. Comparison between cross-linked polymers and Lipofectimine2000 for gene delivery in EL4 and 3T3 cells .Cells were transfected using optimal conditions established for each polymer. Control: PBS only, no plasmid, no polymer. (A) *, $p<0.01$, as compared to Lipofectamine 2000. (B) *, $p<$ 0.01, as compared to Lipofectamine 2000 and EGDMA-PEI2000-2h. $N=6$, error bars represent standard deviation). 
In conclusion, the three cross-linked polymers investigated here are desirable for practical gene transfer application. By employing a properly selected combination of PEIs and potentially biodegradable cross-linking agents, both the in vitro and in vivo gene delivery by PEIs are evidently enhanced, and it is likely to obtain some degradable polyethylenimine derivatives with low toxicity for highly efficient gene delivery when the methodology described herein is adapted to high-throughput synthesis. We are currently further elaborating on the structure-activity-cytotoxicity relationships for this class of polymers.

\section{Experimental Section (materials and methods)}

\section{Plasmid DNA}

Transfections were performed using $2 \mu \mathrm{g}$ per well (in 24-well plates) of plasmids containing the enhanced green fluorescent protein gene (pEGFP-C1) (Clontech, USA). The plasmids were amplified and purified according to standard molecular biology techniques.

Cell culture

Murine B16F10 melanoma cell lines were obtained from ATCC. NIH 3 T3 murine fibroblasts cell lines and 293T (human embryonal kidney) cell lines were purchased from the Institute of Shanghai Biochemistry and Cell Biology, Chinese Academy of Science. NIH-3T3, 293T and B16F10 were cultured in DMEM with 10\% fetal calf serum (FCS). All cell culture media were supplemented with 2 mM L-glutamine (Gibco BRL, USA), 100 units/ml penicillin (Gibco BRL, USA), and $100 \mu \mathrm{g} / \mathrm{ml}$ streptomycin (Gibco BRL, USA). Cells were maintained at $37{ }^{\circ} \mathrm{C}$ in a $5 \% \mathrm{CO}_{2}$ humidified atmosphere. When $80 \%$ confluent, cells were detached with trypsin/EDTA (Gibco BRL, USA), then dispersed and cultured in normal growth media.

\section{Polymer synthesis}

Branched 2000 Da PEI, branched 25-kDa PEI, ethyleneglycol dimethacrylate (EGDMA) and 1, 4butanediol diacrylate (BDDA) were purchased from Sigma-Aldrich USA, and used without further purification unless noted otherwise. Cross-linking was performed following the procedure of Lynn et al. [36, 37]. One gram of PEI (branched, $2000 \mathrm{Da}$ ) was transferred to a $10 \mathrm{ml}$ vial and dissolved in $3 \mathrm{ml}$ of freshly distilled methylene chloride. An equimolar amount of diacrylate linker (ethyleneglycol dimethacrylate or 1, 4-butanediol diacrylate) was added, and the flask was sealed with a solventresistant cap. The reaction was carried out at $45^{\circ} \mathrm{C}$, with shaking, for several hours. The polymer was then precipitated with ether, lyophilized (Labconco 18L Freeze-Dry System, Kansas City, MO, USA), and stored at $-70^{\circ} \mathrm{C}$.

\section{Complex formation, transfection and EGFP expression}

Polymer stock and DNA solutions were prepared before each experiment. Polymer was dissolved in PBS (140 mM NaCl, $2.7 \mathrm{mM} \mathrm{KCl,} 10 \mathrm{mM} \mathrm{Na} \mathrm{HPO}_{4}, 1.8 \mathrm{mM} \mathrm{KH} \mathrm{PO}_{4}, \mathrm{pH} 7.4$ ) as 1mg/ml stock solution. DNA/polymer complexes (polyplexes) were prepared in PBS by the addition of appropriate volume of polymer to the solution of $2 \mu \mathrm{g}$ of plasmid to achieve the desired ratio of polymer to DNA. Polyplexes were then incubated at $25^{\circ} \mathrm{C}$ for $10-15$ min. Cells were cultured in DMEM according to 
ATCC protocols and dispersed in 24 -well plates at $1 \times 10^{5}$ cells/well $24 \mathrm{~h}$ prior to transfection. At the time of transfection, cells were at about $70-80 \%$ confluency. Immediately before transfection, the normal DMEM growth medium was replaced with $200 \mu \mathrm{l}$ serum-free medium and $100 \mu \mathrm{l}$ of polyplexes ( $2 \mu \mathrm{g}$ plasmid/well) each well. Transfection medium was replaced with growth medium $4 \mathrm{~h}$ post transfection. EGFP expression was quantified $24 \mathrm{~h}$ later by flow cytometry (FACS Calibur), Flow cytometry was carried out by counting the number of GFP-expressing cells in the population of 10,000 viable cells. Cytometric analyses were performed using CellQuest (Becton Dickinson) software. All samples were experimented in triplicate and then repeated two or more times independently.

\section{Cytotoxicity assay}

The cytotoxicity of the polymers was measured by MTT assay. B16F10 cells or other cells were seeded at a density of $1 \times 10^{4}$ cells/well in 96-well plates and incubated for $24 \mathrm{~h}$. Prepared polymer complexes were added into cells in the absence of $10 \%$ fetal calf serum. After 4 hours, the polymercontaining medium was removed, $100 \mu \mathrm{l}$ conventional growth media and $20 \mu \mathrm{lof} 5 \mathrm{mg} / \mathrm{ml} \mathrm{MTT}$ in PBS buffer were added. Plates were incubated for additional $4 \mathrm{~h}$ at $37^{\circ} \mathrm{C}$. MTT-containing medium was removed and $100 \mu \mathrm{l}$ of DMSO was added to dissolve the formazan crystal formed by live cells. Absorbance was measured at $570 \mathrm{~nm}$ using a microplate reader (Molecular Devices Co., Menlo Park, CA, USA) and recorded as a percentage relative to untreated control cells.

\section{Particle size measurements}

Polyplex sizes were measured by dynamic light scattering using a Brookhaven 90PLUS particle size analyzer (Brookhaven Instruments Corporation, Holtsville, NY, USA) at $25^{\circ} \mathrm{C}$. Polyplex sizes are expressed as effective diameters (based on intensity weighted analysis). Complexes were prepared as in transfection experiments, except that the amounts of PEI and DNA were scaled up to a total volume of $1.5 \mathrm{ml}$ of polyplexes from $100 \mu \mathrm{l}$. Specifically, appropriate amounts of PEI (for various polymer/DNA ratios) in $750 \mu \mathrm{l}$ of $\mathrm{ddH}_{2} \mathrm{O} / \mathrm{PBS}$ were added to $30 \mu \mathrm{g}$ of DNA in $750 \mu \mathrm{l}$ of $\mathrm{ddH}_{2} \mathrm{O} / \mathrm{PBS}$. This procedure was followed by pipette mixing and incubation at room temperature for 10-15 min, and the polyplexes were then subjected to light scattering experiments. The results were expressed as a mean $\pm \mathrm{SD}, \mathrm{n}=3$.

\section{Gene delivery in mice}

pEGFP-C1 DNAs (Clontech, USA) in $\mathrm{ddH}_{2} \mathrm{O}$, mixed with EGDMA-PEI 2000-2h solution (1 $\mathrm{mg} / \mathrm{ml}$ ) in PBS at indicated polymer/DNA ratios, were incubated at room temperature for 10-15 min. Mouse legs were exposed by removing hair and fifty microliters of the mixture containing $10 \mu \mathrm{g}$ of DNA were administered into the leg muscles of 8-week-old male C57BL/6J mice (Shanghai Laboratory Animal Center, China) using a Hamilton syringe in a proximal to distal direction. Mice were sacrificed at different time points $(1,3,5$, and 7 days) and muscles ( $\mathrm{n}=6$ for each point) were removed, and stored at $-70{ }^{\circ} \mathrm{C}$, then frozen sections were immediately made to evaluate the gene transfection efficiency of 25-kDa branched PEI and the cross-linked PEI through observing the EGFP expression by fluorescence microscopy. 


\section{Statistics and Presentation of Data}

All experiments were repeated at least three times. All numerical data were expressed as mean \pm S.D. Data were analyzed using the two-tailed $t$ test.

\section{Acknowledgements}

This study was supported by the following funds to Zi-Chun Hua: the Chinese National Nature Science Foundation (30330530, 30425009), the Ministry of Education of China (TRAPOYT 1999028418, 111 Project). We thank Ms. Xiao-feng Huang and Ms. Wen-hui Jiang for their assistance with frozen section (Nanjing Stomatology Hospital), and also thank Prof. Zhang Junfeng (Nanjing University) for the generously providing their equipments and facilities.

\section{References}

1. Check, E. Gene therapy: a tragic setback. Nature 2002, 420, 116-118.

2. Hacein-Bey-Abina, S.; Von Kalle, C.; Schmidt, M. et al.. LMO2-associated clonal T cell proliferation in two patients after gene therapy for SCID-X1. Science 2003, 302, 415-419.

3. Luo, D.; Saltzman, W. M. Synthetic DNA delivery system. Nat. Biotechnol 2000, 18, 33-37.

4. Felgner, P. L. Nonviral strategies for gene therapy. Sci. Am. 1997, 276, 102-106.

5. Zauner, W.; Ogris, M.; Wagner, E. Polylysine-based transfection systems utilizing receptormediated delivery. Adv. Drug Delivery Rev. 1998, 30, 98-113.

6. Kircheis, R.; Wightman, L.; Wagner, E. Design and gene delivery activity of modified polyethylenimines. Adv. Drug Delivery Rev. 2001, 53, 341-358.

7. Miller, A. D. Cationic Liposomes for Gene Therapy. Angew. Chem., Int. Ed. Engl. 1998, 37, 17681785 .

8. Godbey, W. T.; Wu, K. K.; Mikos, A. G. Tracking the intracellular path of poly(ethylenimine)/DNA complexes for gene delivery. Proc. Natl. Acad. Sci. USA 1999, 96, 51775181.

9. Zabner, J. Cationic lipids used in gene transfer. Adv. Drug Delivery Rev. 1997, 27, 17-28.

10. Anderson, D. G.; Lynn, D. M.; Langer, R. Semi-automated synthesis and screening of a large library of degradable cationic polymers for gene delivery. Angew. Chem., Int. Ed. Engl. 2003, 42, 3153-3158.

11. Akinc, A.; Lynn, D. M.; Anderson, D. G. et al. Parallel synthesis and biophysical characterization of a degradable polymer library for gene delivery. J. Am. Chem. Soc. 2003, 125, 5316-5323.

12. Thomas, M.; Ge, Q.; Lu, J. J. et al. Cross-linked small polyethylenimines: while still nontoxic, deliver DNA efficiently to mammalian cells in vitri and in vivo. Pharmaceutical Research 2005, 22, 373-380.

13. Ahn, C. H.; Chae, S. Y.; Bae, Y. H. et al. Biodegradable poly(ethylenimine) for plasmid DNA delivery. J. Controlled Release 2002, 80, 273-282.

14. Jon, S.; Anderson, D. G.; Langer, R. Degradable poly(amino alcohol esters) as potential DNA vectors with low cytotoxicity. Biomacromolecules 2003, 4, 1759-1762. 
15. Anderson, D. G.; Peng, W.; Akinc, A. et al. A polymer library approach to suicide gene therapy for cancer. Proc. Natl. Acad.Sci. USA. 2004, 101, 16028-16033.

16. Lim, Y.-B.; Kim, S.-M.; Suh, H. et al. Biodegradable, endosome disruptive, and cationic networktype polymer as a highly efficient and non-toxic gene delivery carrier. Bioconjug. Chem. 2002, 13, 952-957.

17. Forrest, M. L.; Koerber, J. T.; Pack, D. W. A degradable polyethylenimine derivative with low toxicity for highly efficient gene delivery. Bioconjugate Chem. 2003, 14, 934-940.

18. Godbey, W. T.; Wu, K. K.; Mikos, A. G. Poly-(ethylenimine) and its role in gene delivery. $J$. Controlled Release 1999, 60, 149-160.

19. Boussif, O.; Lezoualc'h, F.; Zanta, M. A. et al. A versatile vector for gene and oligonucleotide transfer into cells in culture and in vivo: Polyethylenimine. Proc. Natl. Acad. Sci. USA. 1995, 92, 7297-7301.

20. Coll, J. L.; Chollet, P.; Brambilla, E. et al. In Vivo Delivery to Tumors of DNA Complexed with Linear Polyethylenimine. Hum. Gene Ther. 1999, 10, 1659-1666.

21. Antoine, Kichler. Gene transfer with modified polyethylenimines. J Gene Med. 2004, 6, S3-S10.

22. Abdallah, B.; Hassan, A.; Benoist, C. et al. A powerful nonviral vector for in vivo gene transfer into the adult mammalian brain: polyethylenimine. Hum. Gene Ther 1996, 7, 1947-1954.

23. Putnam, D.; Langer, R. Poly(4-hydroxy-L-proline ester): Low-Temperature Polycondensation and Plasmid DNA Complexation. Macromolecules 1999, 32, 3658-3662.

24. Boussif, O.; Zanta, M. A.; Behr, J.-P. Optimized galenics improve in vitro gene transfer with cationic molecules up to 1000-fold. Gene Ther. 1996, 3, 1074-1080.

25. Godbey, W. T.; Barry, M. A.; Saggau, P. et al. Poly(ethylenimine)-mediated transfection: a new paradigm for gene delivery. J. Biomed. Mater. Res. 2000, 51, 321-328.

26. Goula, D.; Remy, JS; Erbacher, P. et al. Size, diffusibility and transfection performance of linear PEI/DNA complexes in the mouse central nervous system. Gene Ther. 1998, 5, 712-717.

27. Ogris, M.; Steinlein, P.; Kursa, M. et al. The size of DNA/transferrin-PEI complexes is an important factor for gene expression in cultured cells. Gene Ther. 1998, 5, 1425-1433.

28. Thomas, M.; Klibanov, A. M. Enhancing polyethylenimine's delivery of plasmid DNA into mammalian cells. Proc. Natl. Acad. Sci. USA 2002, 99, 14640-14645.

29. Godbey, W. T.; Wu, K. K.; Mikos, A. G. Size matters: molecular weight affects the efficiency of poly(ethylenimine) as a gene delivery vehicle. J. Biomed. Mater. Res. 1999, 45, 268-275.

30. Daniel, G.; Anderson, A. A.; Naushad, H. Structure/property studies of polymeric gene delivery using a library of poly( $\beta$-amino esters). Mol. Ther. 2005, 11, 426-434.

31. Zhong, Zhiyuan; Yan, Song; Johan, F. J. et al. A versatile family of degradable non-viral gene carriers based on hyperbranched poly(ester amine)s. J. Control. Release 2005, 109, 317-329.

32. Massimo, Don; Marco, Sandri; Katia, Rossini et al. Functional in vivo gene transfer into the myofibers of adult skeletal muscle. Biochem Bioph Res Co 2003, 312, 1132-1138.

33. Li, Shufeng; Dong, Wei; Zong, Yiwei et al. Polyethylenimine-complexed Plasmid Particles Targeting Focal Adhesion Kinase Function as Melanoma Tumor Therapeutics. Mol. Ther. 2007, in press 
34. Kunath, K.; Harpe, A. V; Fisher, D. et al. Low-molecular-weight polyethylenimine as a non-viral vector for DNA delivery: comparision of physicochemical properties, transfection efficiency and in vivo distribution with high-molecular-weight polyethylenimine. J. Control. Release 2003, 89, 113-125.

35. Sharma, V. K.; Thomas, M.; Klibanov, A. M. Mechanistic studies on aggregation of polyethylenimine-DNA complexes and its prevention. Biotechnology and Bioengineering 2005, 90, 614-620.

36. Lynn, D. M.; Anderson, D. G.; Putnam, D. et al. Accelerated discovery of synthetic transfection vectors: Parallel synthesis and screening of a degradable polymer library. J. Am. Chem. Soc. 2001, $123,8155-8156$.

37. Lynn, D. M.; Langer, R. Degradable poly( $\beta$-amino esters): synthesis, characterization, and selfassembly with plasmid DNA. J. Am. Chem. Soc. 2000, 122, 10761-10768.

(C) 2007 by MDPI (http://www.mdpi.org). Reproduction is permitted for noncommercial purposes. 